\title{
DR. SOFT ON MARRIAGE
}

Your life depends on it.

It troubles the doctor less

that women he knows and loves

and is married to

have been married before

than that

priority

they put

on marriage

where, for the doctor,

marriage is the most immediate

fact in his life

that it's an institution

he feels in his bones

that

any

incapacity

for marriage

to anything

is cause for concern

for the doctor

is Dr. Soft

Dr. Soft on marriage.

The man the doctor is thinking of is Paul Blackburn and the city is New York

and the gentleness

of someone

the gentleness

how, what there was, was shared

that it was manly

that there were no lies

that the first writer he knew

capable of love in this way

was this man. 
Drano in the kitchen sink that lye never works to unclear anything but is of use solely

as a precaution

that if it's a confession

the doctor is reading and a piece of literature

that purports or pretends or appears

to come out of that confessional

the doctor's choice

is for the former

and to hell with the other.

Similarly, regarding epigraphs

quotes "from my sister's dentist"

and elsewhere

how nothing published in the last 75 years

has been equal to its own epigraph.

More marvelous than anything I can imagine:

being read. Anyone

reading

any one word

of this. 